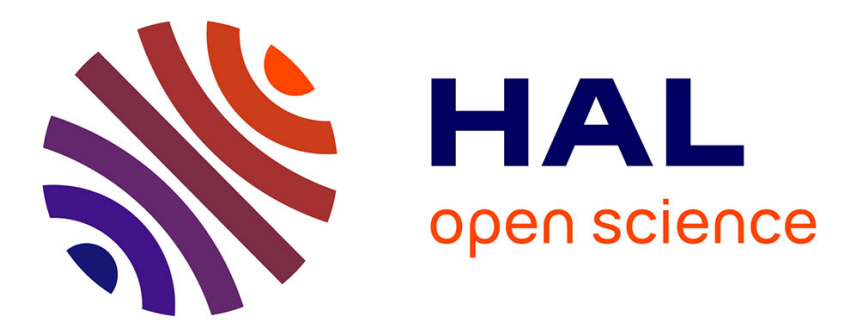

\title{
Structural, morphological, optical and electrical characterization of InGaN/GaN MQW structures for optoelectronic applications
}

K. Prabakaran, M. Jayasakthi, S. Surender, S. Pradeep, S. Sanjay, R. Ramesh, M. Balaji, Nicolas Gautier, K. Baskar

\section{To cite this version:}

K. Prabakaran, M. Jayasakthi, S. Surender, S. Pradeep, S. Sanjay, et al.. Structural, morphological, optical and electrical characterization of InGaN/GaN MQW structures for optoelectronic applications. Applied Surface Science, 2019, 476, pp.993-999. 10.1016/j.apsusc.2019.01.156 . hal-02079849

\section{HAL Id: hal-02079849 \\ https://hal.science/hal-02079849}

Submitted on 3 Jun 2020

HAL is a multi-disciplinary open access archive for the deposit and dissemination of scientific research documents, whether they are published or not. The documents may come from teaching and research institutions in France or abroad, or from public or private research centers.
L'archive ouverte pluridisciplinaire HAL, est destinée au dépôt et à la diffusion de documents scientifiques de niveau recherche, publiés ou non, émanant des établissements d'enseignement et de recherche français ou étrangers, des laboratoires publics ou privés. 


\title{
Structural, morphological, optical and electrical characterization of InGaN/ GaN MQW structures for optoelectronic applications
}

\author{
K. Prabakaran a,*, M. Jayasakthi ${ }^{\mathrm{a}}$, S. Surender ${ }^{\mathrm{a}}$, S. Pradeep ${ }^{\mathrm{a}}$, S. Sanjay ${ }^{\mathrm{a}}$, R. Ramesh ${ }^{\mathrm{c}}$, M. Balaji $^{\mathrm{d}}$, \\ Nicolas Gautier ${ }^{\mathrm{e}}$, K. Baskar ${ }^{\mathrm{a}, \mathrm{b}, *}$ \\ ${ }^{a}$ Crystal Growth Centre, Anna University, Chennai, India \\ ${ }^{\mathrm{b}}$ Manonmaniam Sundaranar University, Tirunelveli, India \\ ${ }^{\mathrm{c}}$ Department of Electronics and Nanoengineering, Aalto University, Finland \\ ${ }^{\mathrm{d}}$ Department of Energy, University of Madras, Guindy Campus, Chennai, India \\ ${ }^{\mathrm{e}}$ Institut des Matériaux Jean Rouxel, UMR 6502 CNRS Université de Nantes, France
}

InGaN/GaN multiple quantum well (MQW) structures were grown on c-plane sapphire substrate using metal organic chemical vapour deposition technique by varying the MQW periods. The indium composition and thickness were estimated using high-resolution X-ray diffraction. InGaN well, GaN barriers and Indium composition were estimated as $3 \mathrm{~nm}, 18 \mathrm{~nm}$ and 16-18\% using epitaxy smooth fit software. Reciprocal space mapping revealed that InGaN/GaN MQW samples were coherently strained. High-resolution transmission electron microscopy images confirmed good interface between the InGaN/GaN MQW structures. Atomic force microscopy and scanning electron microscopy exhibit decrease in the surface roughness with increase in the number of InGaN/GaN MQW periods with respect to the number of defects comprising of threading dislocations and hexagonal V-pits. Self-organized $\mathrm{In}(\mathrm{Ga}) \mathrm{N}$ like nanostructures with spiral growth mechanism was also observed due to the low temperature growth of p-GaN layer. The photoluminescence spectra of the MQWs showed a red-shift when the number of QW periods was increased due to quantum confined stark effect. Hall Effect measurement displayed good semiconducting behavior in the InGaN/GaN MQW structures. The carrier concentration values also emphasized adequate variations when number of periods was increased.

\section{Introduction}

Group III-nitride semiconductors have been an excellent candidate for various applications such as optoelectronics and high power devices [1-4]. They are widely preferred for their outstanding tunable direct bandgap characteristics from near infrared $(\sim 0.7 \mathrm{eV}-\mathrm{InN})$ to ultraviolet region (GaN-3.4 eV) by varying the Indium (In) compositions [5-8]. Comparing with the other semiconducting materials, InGaN attracts more attention due to its high carrier mobility, superior radiation resistance and high optical absorption $\left(\sim 10^{5} \mathrm{~cm}^{-1}\right)$ [5,9-12]. InGaN based optoelectronics devices possess excellent physical and chemical stability that allows them to operate under harsh environments [13,14]. In general, InGaN/GaN multiple quantum well (MQW) structures act as active regions for light emitting diode (LED), solar cells and thermoelectric applications. However, extending the emission range (From green to red) and improve the luminescence property of InGaN is still challenge [15]. Furthermore, to minimize the lattice mismatch between
InN and GaN to obtain InGaN layer with high crystalline quality is another challenge $[6,16,17]$. In order to surmount this intricacy, the InN layers are generally grown at low temperature (LT) due to the thermal decomposition of InN. The growth of thick InGaN layer with comparatively high indium composition is one of the critical challenges in fabricating InGaN-based optoelectronic devices [18]. To overcome these issues, the In-rich thin InGaN layer based MQW structure was used as an alternative. The crystalline quality depends on various parameters such as optimization of barrier, well thickness and growth temperature of MQWs $[17,19]$ along with the In composition of InGaN wells and number of MQW periods. However, the collection of carriers in strained MQWs can be affected considerably by the spontaneous and piezoelectric polarization fields. This phenomenon is known as quantum confinement stark effect (QCSE). It leads to the spatial separation of electron and hole wave functions, which restricts the carrier recombination efficiency [20]. In addition, surface topography of Inrich InGaN based MQW structures aggravates the optical and electrical

\footnotetext{
* Corresponding authors at: Crystal Growth Centre, Anna University, Chennai-25, India.

E-mail addresses: karanphy07@gmail.com (K. Prabakaran), drbaskar2009@gmail.com (K. Baskar).
} 
properties, through high density of structural defects like threading dislocations (TD), V-defects and trench defects during the epitaxial process [21-24]. This also affects the interface of InGaN/GaN MQWs during the growth of $\mathrm{p}$-GaN layers. To avoid such degradation in the quality of InGaN/GaN MQWs, the p-GaN layer is grown at lower temperatures $[3,25]$. A better understanding of structural, morphological, optical and electrical properties of InGaN/GaN MQW structure are necessary to achieve sharp interfaces and atomically flat surface, which enhances the efficiency [23]. In the present work, the effects of increasing the number of periods in MQWs and the effect of growing pGaN layer at low temperature in InGaN/GaN MQW structures have been carried out.

\section{Experimental procedure}

InGaN/GaN MQW structures were grown on 2-inch c-plane sapphire substrate using metal organic chemical vapour deposition (MOCVD, Aixtron200/4RF-S) by varying the period of MQWs. Trimethylgallium (TMGa), Trimethylindium (TMIn) and ammonia $\left(\mathrm{NH}_{3}\right)$ were used as precursors for gallium, indium and nitrogen respectively. Triethylgallium (TEGa) was used as the gallium precursor during the growth of barrier layer in the active region of the structures. Silane and bis-cyclopentadienyl magnesium $\left(\mathrm{Cp}_{2} \mathrm{Mg}\right)$ were used as $\mathrm{n}$ and p-type dopants respectively. High purity hydrogen $\left(\mathrm{H}_{2}\right)$ and nitrogen $\left(\mathrm{N}_{2}\right)$ were used as carrier gases. Prior to the growth, the sapphire substrates were thermally cleaned under $\mathrm{H}_{2}$ ambience at $1050^{\circ} \mathrm{C}$ for $10 \mathrm{~min}$ to remove residues and impurities on the surface. Subsequently, $25 \mathrm{~nm}$ thick GaN nucleation layer (NL) was grown at $520^{\circ} \mathrm{C}$ with a V/III ratio of 3453 . GaN NL was recrystallized at $1000^{\circ} \mathrm{C}$ for $1 \mathrm{~min}$. The growth temperature was ramped up to $1010{ }^{\circ} \mathrm{C}$ and a $2 \mu \mathrm{m}$ thick $\mathrm{n}-\mathrm{GaN} / \mathrm{GaN}$ was grown (carrier concentration - $2.48 \times 10^{18} \mathrm{~cm}^{-3}$ ) [26] using $\mathrm{H}_{2}$. Silane flow rate for Si-GaN layer was maintained at 40 standard cubic centimeters per minute (SCCM) with a V/III ratio of 614. The InGaN/ GaN MQW (one, three and five periods) structures comprising of InGaN wells were grown at $720^{\circ} \mathrm{C}$ with V/III ratio 11,625 (TMIn flow$13 \mu \mathrm{mol} / \mathrm{min} \& \mathrm{TEG}$ flow rate $-6.2 \mu \mathrm{mol} / \mathrm{min}$ ) and the GaN barriers at $820^{\circ} \mathrm{C}$. Finally, $\mathrm{Cp}_{2} \mathrm{Mg}$ flow rate for $\mathrm{Mg}$-GaN layer was $300 \mathrm{SCCM}$ grown at $920^{\circ} \mathrm{C}$, continue to In-situ annealing at $700{ }^{\circ} \mathrm{C}$ for $15 \mathrm{~min}$ in all samples. Schematic view of the structures has been shown in the Fig. 1.

The crystalline quality, composition and thickness of the InGaN/ GaN MQW structures were determined using High resolution X-ray Diffractometer (HRXRD-PANalytical X'Pert Pro MRD). The morphology of InGaN/GaN MQW and the interfaces were performed using a High resolution transmission electron microscopy (HRTEM) (Hitachi, H9000-NAR, $\mathrm{LaB}_{6}$ filament, $300 \mathrm{kV}$, point to point resolution: $0.18 \mathrm{~nm}$ ). Cross-section TEM samples were prepared by tripod polishing and

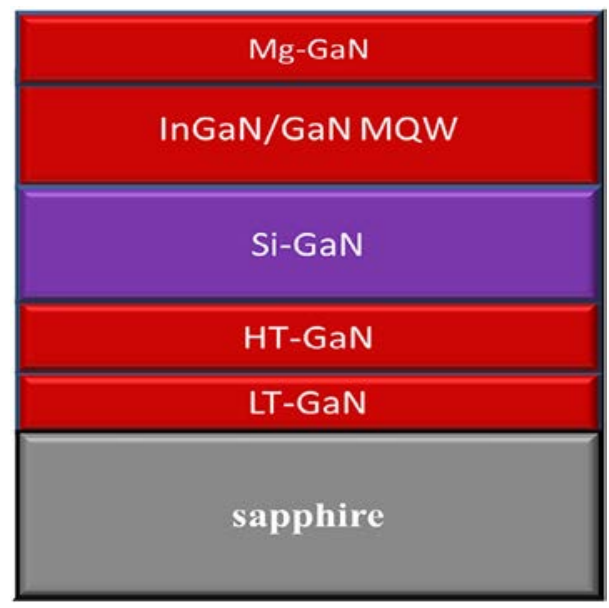

Fig. 1. Schematic diagram of the InGaN/GaN MQW structures. subsequently polished with $\mathrm{Ar}^{+}$ion using Gatan precision ion polishing system (PIPS).The surface properties and roughness were analyzed by scanning electron microscopy (SEM, Carl Zeiss EVO18), atomic force microscopy (AFM, Park XE-100) respectively. Photoluminescence (PL, Spectra Physics) of the samples were measured at room temperature by $244 \mathrm{~nm} \mathrm{Ar}^{+}$laser. The electrical properties of the samples were measured using hall measurement system (ECOPIA, HMS 5000).

\section{Results and discussion}

\subsection{Structural analysis}

Fig. 2 illustrates the $\omega-2 \theta$ scan of MQW structures were observed using HRXRD. Thicknesses and In compositions of the InGaN MQWs were obtained from the symmetric scans of $\left(\begin{array}{llll}0 & 0 & 0 & 2\end{array}\right)$ plane. Using the epitaxy smooth fit software (Fig. 2(III)), the InGaN well and GaN barrier thickness were determined as $3 \pm 0.5 \mathrm{~nm}$ and $18 \pm 0.5 \mathrm{~nm}$ respectively. The In compositions were estimated around $\sim 16-18 \%$. From the obtained HRXRD results, the high intense peaks manifests that, the grown $\mathrm{n}-\mathrm{GaN} / \mathrm{GaN}$ is oriented along ( $\left(\begin{array}{llll}0 & 0 & 0 & 2\end{array}\right)$ plane. The satellite peaks observed illustrates good periodicity in the MQW layers (Fig. 2(II)). It is worth to note that, the absence of satellite peaks in one period InGaN/ GaN QW (Fig. 2(I)), emphasize the non-uniformity in the InGaN/GaN interface which is evident from its surface roughness [27]. The full width at half maximum (FWHM) broadening of three periods InGaN/ GaN MQWs improved the crystalline randomization by exposing less interface roughness between InGaN and $\mathrm{GaN}$ layers in comparison to one period QW structure [28]. Also, the satellite peak narrowing of five periods InGaN/GaN MQW revealed the interface is atomically flat when compared with the other two samples (Fig. 2(II)). Among the three samples, the InGaN/GaN MQW structures grown at five periods exhibits better crystallinity [29].

The rocking-curve analysis in respect of $\mathrm{GaN}$ was carried out for all the samples. The FWHM of $\left(\begin{array}{llll}0 & 0 & 0 & 2\end{array}\right)$ plane rocking curve of GaN are estimated as 400,370 and 372 arc sec, whereas for (1 0-15) it is 242 , 230 and 246 arc sec. The TD density was calculated from the below equations [30],

$D_{\text {edge }}=\frac{\beta^{2}}{4.35\left|b_{\text {edge }}\right|^{2}} D_{\text {Screw }}=\frac{\alpha^{2}}{4.35\left|b_{\text {screw }}\right|^{2}}$

where $D_{\text {edge }}$ is the edge dislocation density, $D_{\text {screw }}$ is the screw dislocation density and $\alpha, \beta$ refers to FWHM value measured from rocking

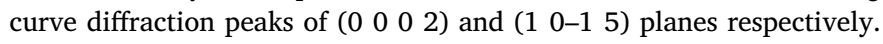
Here, lattice constant $a$-axis $(0.31878 \mathrm{~nm})$ is the length of the burger vector for the edge dislocation density and $c$-axis $(0.5185 \mathrm{~nm})$ is the length of the burger vector of the screw dislocation density [31]. The calculated TD density of GaN layers of the three samples are shown in Table 1 . The TD density of GaN was found to be in the range from $6.32 \times 10^{8}$ to $5.99 \times 10^{8} \mathrm{~cm}^{-2}$. The TD density in GaN base layer for three periods of InGaN/GaN MQW structure was lesser in comparison to the other two samples. This is attributed to the low tilt and twist disorientations with respect to the screw and edge dislocations originating from $\mathrm{n}-\mathrm{GaN} / \mathrm{GaN}$ layer.

Fig. 3 shows the reciprocal space mapping (RSM) corresponding to the asymmetric (1 0-1 5) plane of InGaN/GaN MQW structures for one, three and five periods respectively. The high intensity GaN peak is observed on the intense contour lines in all the RSM studies and the InGaN/GaN MQW peaks are observed below the GaN peak. Using the epitaxy smooth fit software, the reciprocal lattice point (RLP) of $Q_{x}$ values was found to be $0.279046 \mathrm{rlu}$ and $0.277604 \mathrm{rlu}$ for the GaN buffer layer and corresponding peaks of three and five periods of InGaN/GaN MQWs respectively which indicates that the GaN layer, InGaN well and GaN barriers which accommodating on identical inplane lattice constants. As the critical thickness of the barrier and wells in the InGaN/GaN MQW structures did not exceed, the overlying InGaN 

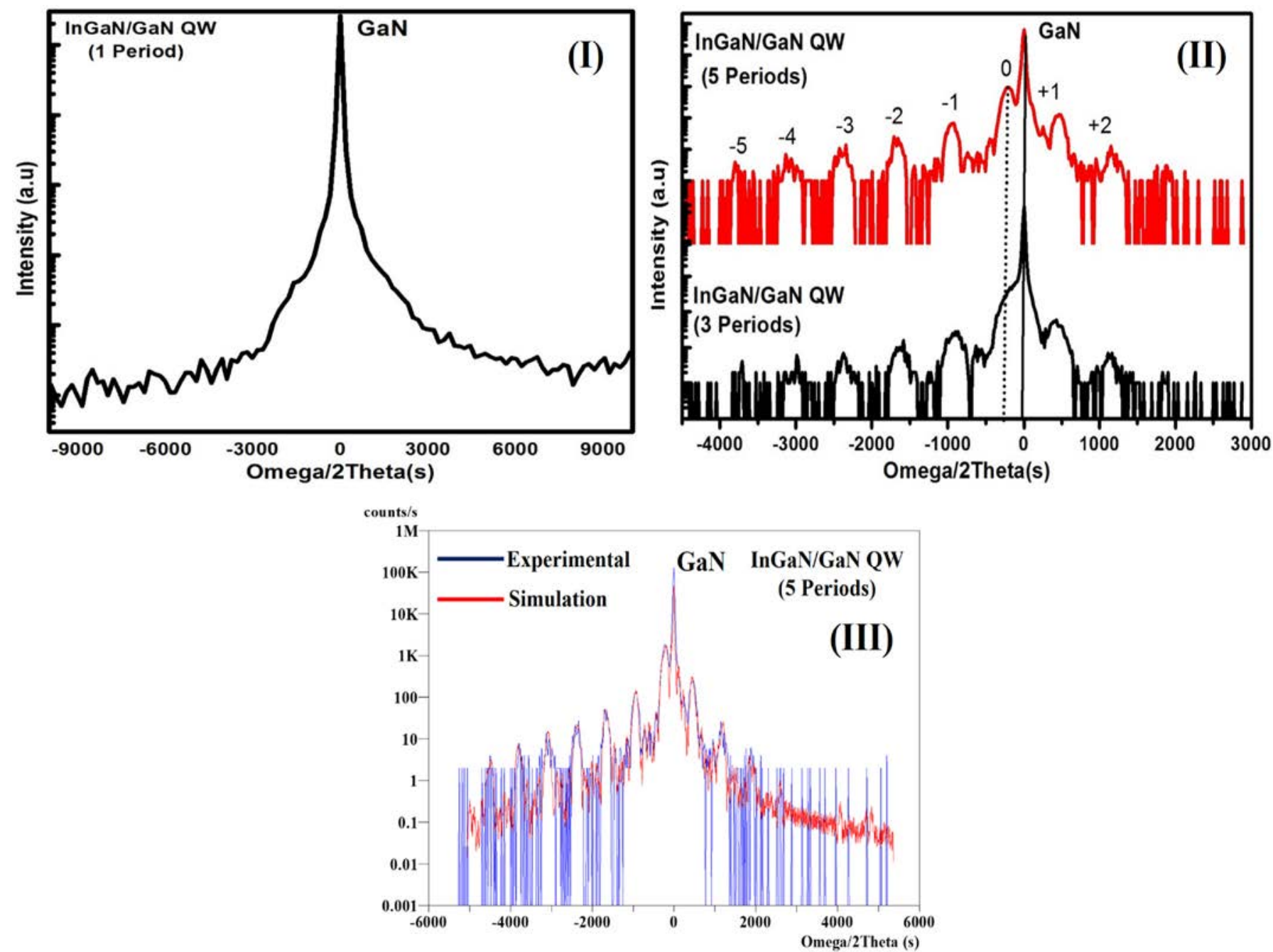

Fig. 2. HRXRD ( $\left.\begin{array}{llll}0 & 0 & 0 & 2\end{array}\right)$ plane of (I) InGaN/GaN QW (one period) structure.

(II) InGaN/GaN MQW (three and five periods) structure (III) InGaN/GaN MQW (five periods) for experimental (blue line) along with simulation (red line).

Table 1

Summary of GaN dislocation densities in the InGaN/GaN MQW structures.

\begin{tabular}{llcc}
\hline Samples & \multicolumn{2}{l}{ GaN dislocations in the InGaN/GaN MQW structures } & \\
\cline { 2 - 4 } & $\begin{array}{l}\text { Screw dislocations } \\
\left(10^{8} \mathrm{~cm}^{-2}\right)\end{array}$ & $\begin{array}{l}\text { Edge dislocations } \\
\left(10^{8} \mathrm{~cm}^{-2}\right)\end{array}$ & TD $\left(10^{8} \mathrm{~cm}^{-2}\right)$ \\
\hline 1 Period & 3.21 & 3.11 & 6.32 \\
3 Periods & 2.75 & 2.81 & 5.56 \\
5 Periods & 2.78 & 3.21 & 5.99 \\
\hline
\end{tabular}

MQWs are coherently strained with respect to the GaN base layer [5]. This reveals that the InGaN/GaN MQWs are pseudomorphic to the GaN layer. The obtained results comply with the Fast Fourier Transformation (FFT) analysis.

Fig. 4 represents the cross-sectional HRTEM images of hexagonal GaN (ICSD\#25676) layer and sapphire substrate (ICSD\#9770) indexed using java electron microscopy software (JEMS) [32]. From figure, it is clear that, the interface between the layer and substrate is atomically flat. The SAED pattern signifies the epitaxial relationship of hexagonal GaN layer on sapphire substrate. The obtained SAED patterns complement the HRXRD results. The GaN/InGaN/GaN interface has exhibited surface morphology that is predominantly free from pits and stacking faults. The cross-sectional bright field TEM images Fig. 5(I, II) show high resolution image of InGaN/GaN MQW (three periods) which further displays the interfaces between the InGaN well (dark) and GaN (bright) barrier layer in InGaN/GaN MQW structures. The thickness of InGaN well and GaN barrier was estimated to be $3 \mathrm{~nm}$ and $20 \mathrm{~nm}$ respectively. Fig. 5(III) shows indexing of the FFT with both InGaN and $\mathrm{GaN}$ layers. The image shows continuous lattice fringes across the GaN/ InGaN/GaN interfaces, with no evidences of a misfit layer formation. FFT analysis confirms that the lattice plane alignments are similar in respect of both InGaN and GaN layers [33]. The zone axis corresponding to $\mathrm{GaN}$ and InGaN layers were found similar to that of the growth direction.

\subsection{Morphological analysis}

Fig. 6 shows the sequence of AFM images comprising of InGaN/GaN MQW (one, three and five periods) structures respectively. The smooth and roughened surfaces of the p-GaN samples were clearly observed. These surface roughnesses of $\mathrm{p}-\mathrm{GaN}$ can be attributed to TDs intersecting the active layer and the formation of $\mathrm{Mg}-\mathrm{H}$ complexes in $\mathrm{p}-\mathrm{GaN}$ layer [34]. The roughness of the $\mathrm{p}-\mathrm{GaN}$ surface decreases the reflection at the $\mathrm{p}-\mathrm{GaN} / \mathrm{air}$ interface which in turn increases the path light through the active region thereby increasing the light absorption of these structures. Rough p-GaN surface usually grows at low temperature, leading to a high growth rate that result in the formation of V-pits [5]. As represented by the $2 \mu \mathrm{m}^{2}$ scans of AFM images, the p-GaN surface was characterized by spiral growth along with self-organized In 

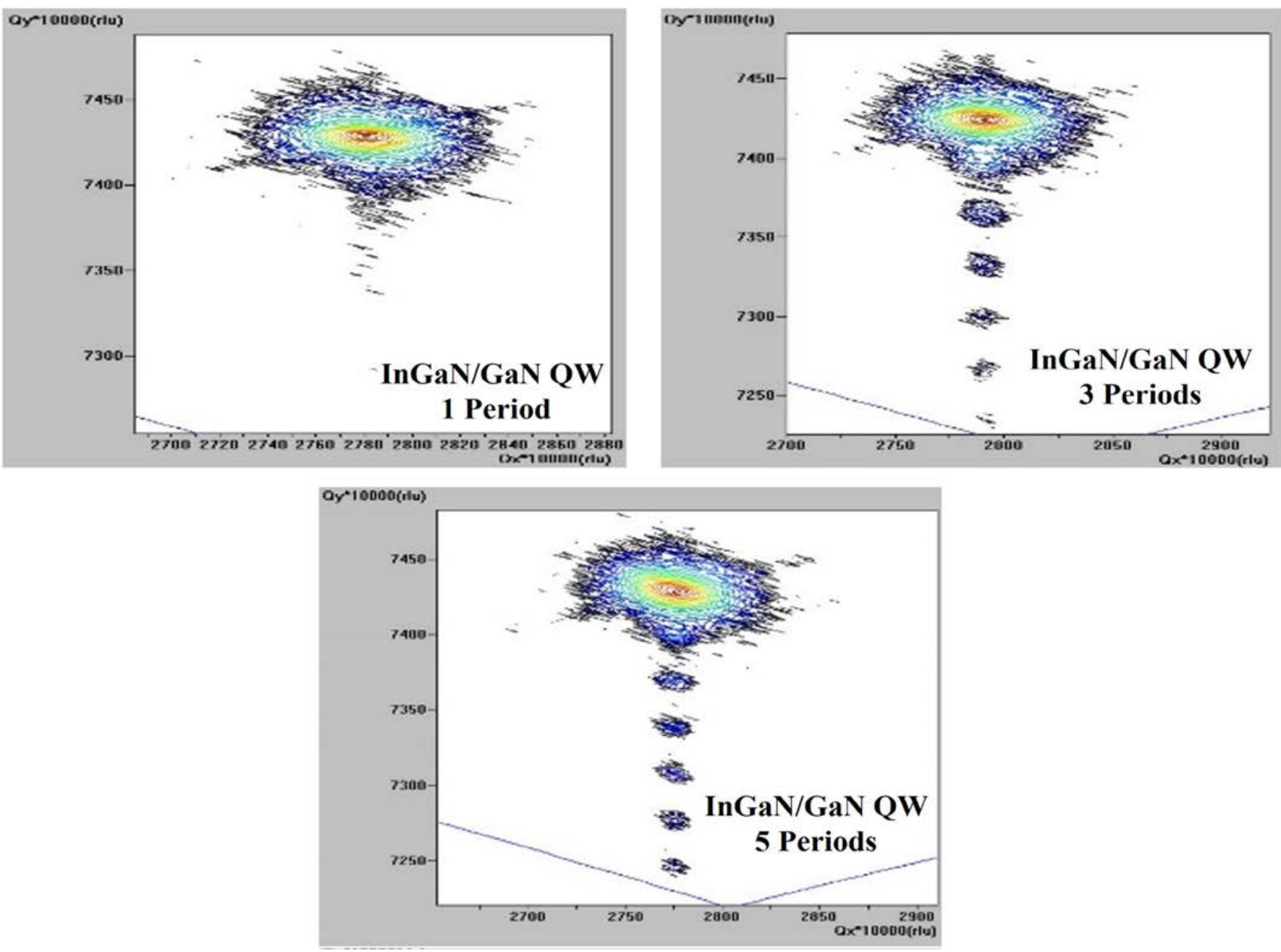

Fig. 3. RSM of the InGaN/GaN MQW structures (one, three, and five periods) along (1 0-1 5) plane.

(Ga)N like nanostructures and shallow type V-pits for one and three periods of InGaN/GaN MQW structures. The five periods of InGaN/GaN MQW structures showed step flow growth besides suppressing the nanostructures on the top of p-GaN layer. The root-mean-squared (RMS) roughness as $0.52 \mathrm{~nm}, 0.26 \mathrm{~nm}$ and $0.145 \mathrm{~nm}$ were observed for one, three and five periods respectively. In contrary, the $5 \mu \mathrm{m}^{2}$ AFM image for five periods showed significantly rough $\mathrm{p}-\mathrm{GaN}$ surface with deep Vpits with considerably large RMS roughness of $29 \mathrm{~nm}$. Fig. 7(I) shows the line profile with the pit around 1-2 $\mu \mathrm{m}$. The observed V-pits were initiated on the TD intersection along the InGaN/GaN QW above the GaN layer (TD density $\sim 10^{8} \mathrm{~cm}^{-2}$ ). The depth of the pit was estimated to be $90-100 \mathrm{~nm}$.

From the Fig. 7(II), the smaller and larger V-pits were observed from the SEM images for InGaN/GaN MQWs (five periods) samples. The Vpit density was calculated and found to be in the order of $0.16 \times 10^{8} \mathrm{~cm}^{-2}$ (Fig. $7($ II)). The smaller V-pits were due to the edge
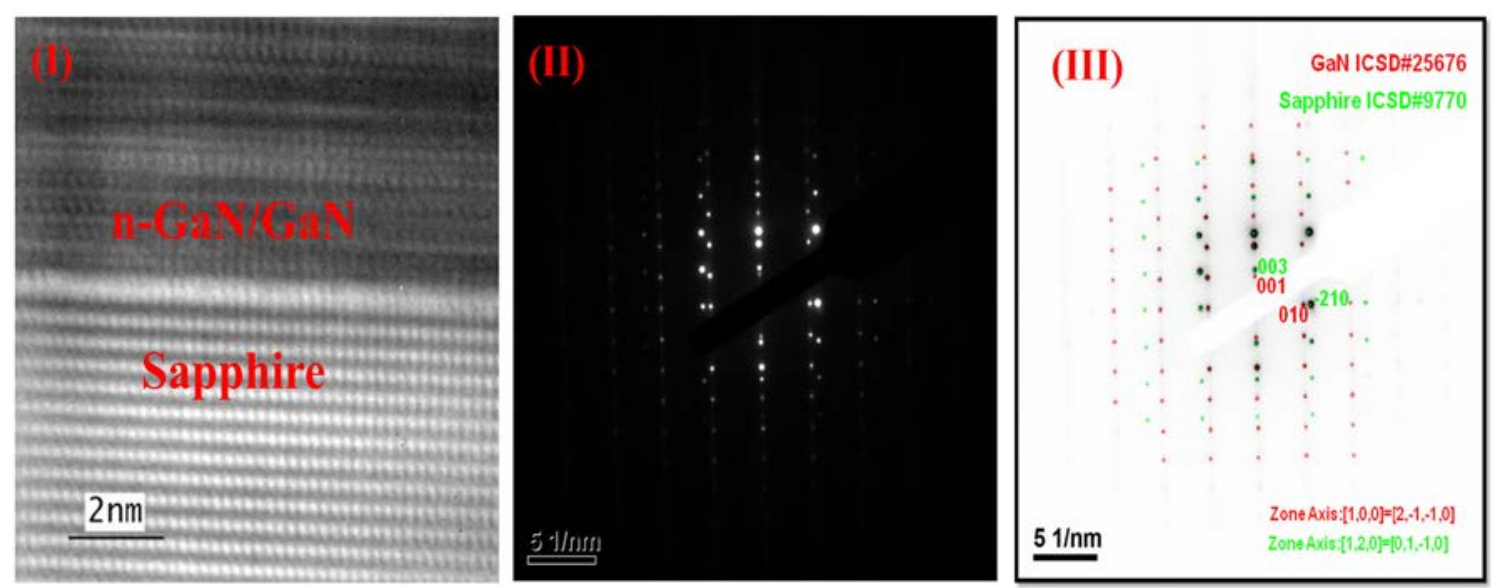

Fig. 4. (I) Interface of n-GaN/GaN/Sapphire (II) Corresponding selected area electronic diffractions (SAED) pattern and (III) simulation with JEMS software. 

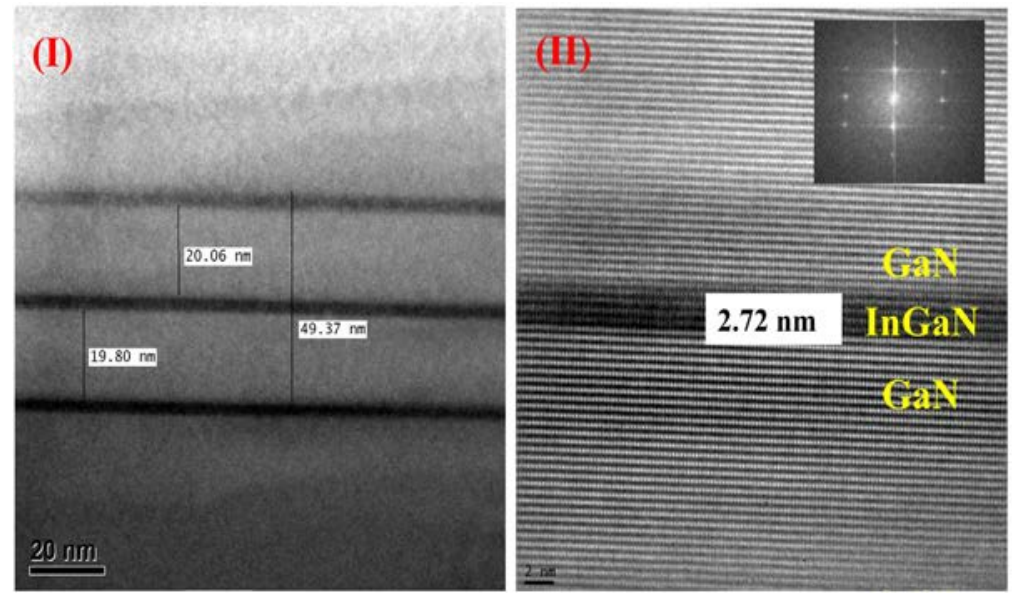

(III)

InGaNICSD\#181363

\section{GaNICSD\#25676}

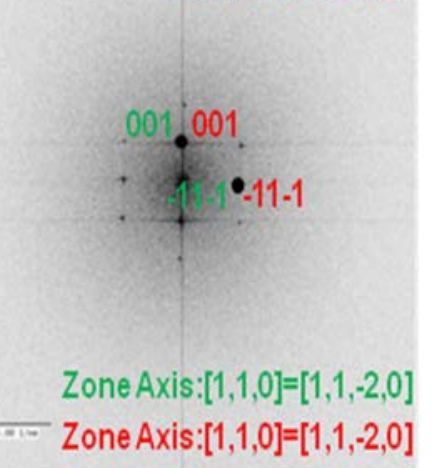

Fig. 5. (I) GaN/InGaN/GaN interfaces representing InGaN/GaN MQW structures (three periods) (II) High resolution TEM of GaN/InGaN/GaN interfaces in three periods of InGaN/GaN MQW structures and corresponding FFT (inset view) (III) Simulation of JEMS software in InGaN and GaN.

TDs and larger V-pits compounds to screw or mixed TDs [35]. This emphasizes that the densities of the V-pits corroborates to the results calculated (TD density) from HRXRD.

\subsection{Optical analysis}

Room temperature PL spectra for the InGaN/GaN MQW structures for different periods were shown in Fig. 8. Near band edge emission (NBE) occurs at $363 \mathrm{~nm}$ for the $\mathrm{n}-\mathrm{GaN} / \mathrm{GaN}$ layer in all samples. The emissions of InGaN/GaN MQW structure were observed at $479 \mathrm{~nm}$, $480 \mathrm{~nm}$ and $505 \mathrm{~nm}$ for one, three and five periods respectively. These peak emissions were found to be red shifted in the InGaN/GaN MQW structures which could be attributed to the QCSE resulting of the modification in polarization effect $[36,37]$. The PL peaks at $479 \mathrm{~nm}$ and $480 \mathrm{~nm}$ wavelength displays poor emission intensity caused by self- organized In(Ga)N like nanostructures. It is worth to note that, the emission at around $383 \mathrm{~nm}(3.2 \mathrm{eV})$ is usually occurs for highly $\mathrm{Mg}$ doped $\mathrm{GaN}$ that is attributed to the transition between the $\mathrm{Mg}$ acceptor $\left(\mathrm{Mg}_{\mathrm{Ga}}\right)$ and deep compensating donor of $\mathrm{Mg}_{\mathrm{Ga}}-\mathrm{V}_{\mathrm{N}}$ complex. However, this does not clearly emerge from the PL spectra due to the lower Mg incorporation and partially reduced nitrogen concentration in one and three periods of the InGaN/GaN MQW structures respectively [38].

The high intense green luminescence peak observed at $505 \mathrm{~nm}$ was may be due to the dislocations and pits on the surface of five period's sample. The $\mathrm{Mg}$ and related transitions shift to $405 \mathrm{~nm}(3 \mathrm{eV})$ in the $\mathrm{Mg}$ doped GaN layers for five period of InGaN/GaN MQW structures, implying enhancement in the $\mathrm{Mg}$ incorporation. This could be attributed to the decrease in the self-compensation effect of native donors and $\mathrm{Mg}$ atoms [39]. One could understand from the above result that the intensity of the red $(660 \mathrm{~nm})$ luminescence is an effect of the strong
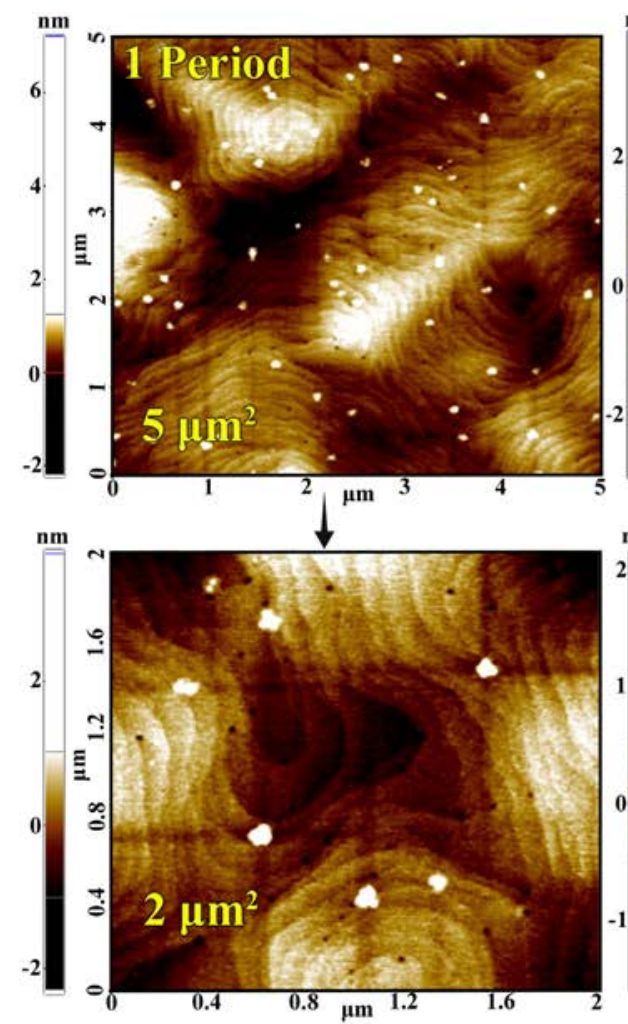

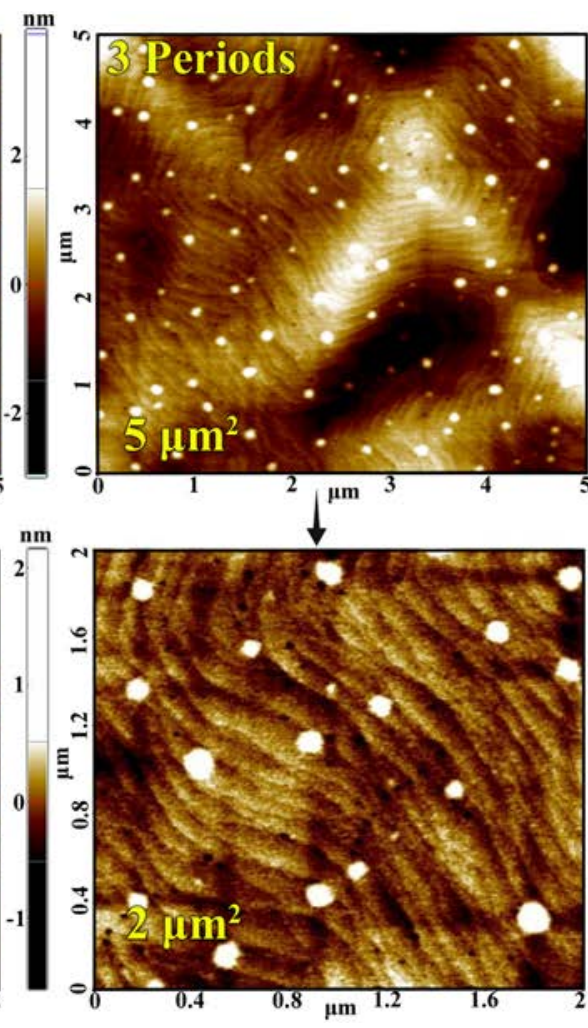

Fig. 6. AFM $\left(5 \mu \mathrm{m}^{2}\right.$ and $\left.2 \mu \mathrm{m}^{2}\right)$ images depicting InGaN/GaN MQW (one, three and five period) structures. 


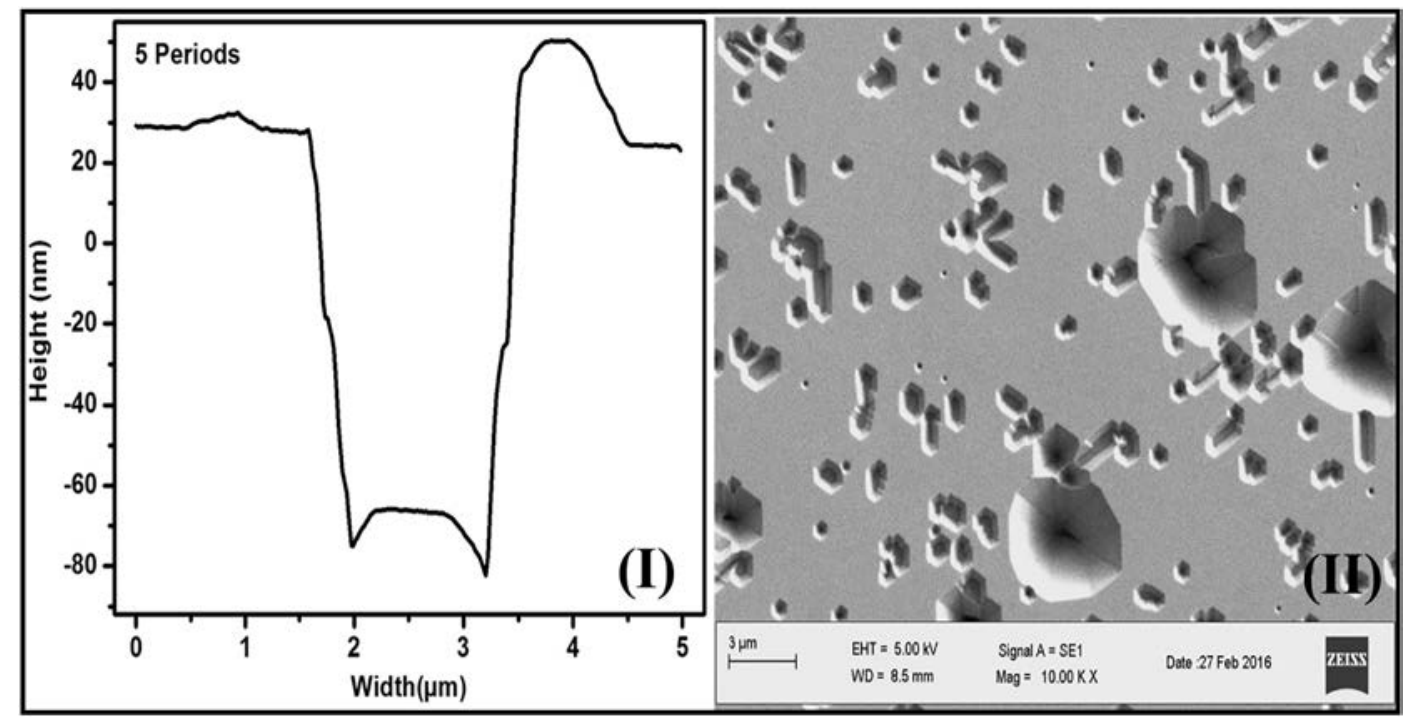

Fig. 7. (I) Line profile obtained from AFM images for five periods (II) SEM images corresponding to (I).

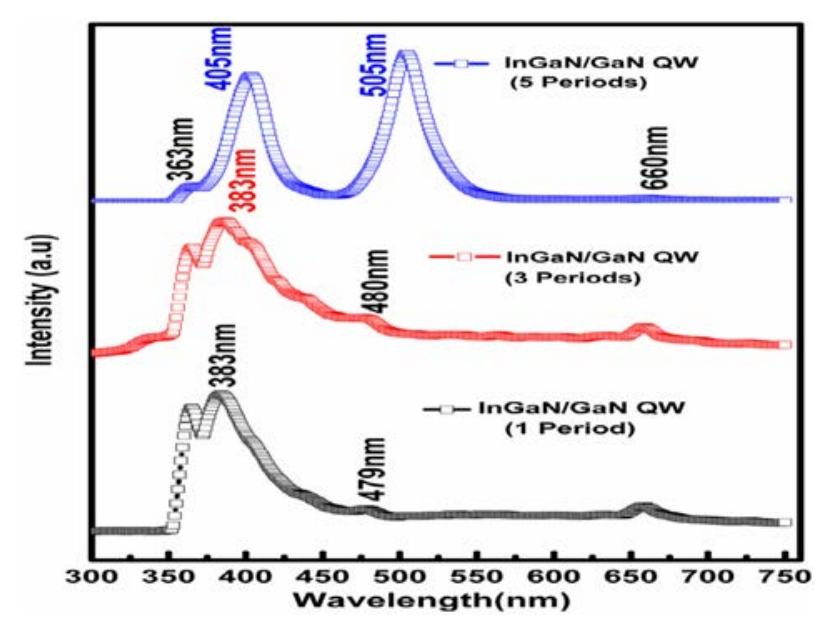

Fig. 8. Photoluminescence spectra of InGaN/GaN MQW structures for different periods.

exciton localization on In-rich small regions in the QW interfaces of InGaN/GaN MQW structures [40].

\subsection{Electrical analysis}

The mobility, carrier concentration and resistivity of the low temperature $\mathrm{p}-\mathrm{GaN}$ with a $\mathrm{Cp}_{2} \mathrm{Mg}$ flow rate of 300 SCCM in respect of the number of periods of the InGaN/GaN MQW structures are shown in Table 2. The carrier concentration increases from $2.26 \times 10^{18}$ to $2.43 \times 10^{18} \mathrm{~cm}^{-3}$ for one and three periods of InGaN/GaN MQW structures. However, the carrier concentration decreases for the five periods of the InGaN/GaN MQW structures. The carrier concentration

Table 2

Electrical properties of the InGaN/GaN MQW structures for different periods.

\begin{tabular}{lccc}
\hline Samples & $\begin{array}{l}\text { Mobility } \\
\mathrm{cm}^{2} / \mathrm{V} \mathrm{s}\end{array}$ & $\begin{array}{l}\text { Carrier concentration } \\
\mathrm{cm}^{-3}\end{array}$ & $\begin{array}{l}\text { Resistivity } \\
\text { ohm-cm }\end{array}$ \\
\cline { 2 - 4 } & $\mathrm{RT}$ & $\mathrm{RT}$ & $\mathrm{RT}$ \\
\hline 1 Period & 290 & $2.26 \times 10^{18}$ & 0.0095 \\
3 Periods & 275 & $2.43 \times 10^{18}$ & 0.0093 \\
5 Periods & 270 & $2.30 \times 10^{18}$ & 0.0099 \\
\hline
\end{tabular}

$\sim 10^{18} \mathrm{~cm}^{-3}$ range point towards the $\mathrm{Mg}$ doped $\mathrm{GaN}$ related band around 3-3.2 eV [41]. The mobility of the samples were found to decrease gradually as $290,275,272 \mathrm{~cm}^{2} / \mathrm{V}$ s for one, three and five periods of InGaN/GaN MQW structures respectively. In the present case, the mobility of low temperature $\mathrm{Mg}$ doped $\mathrm{GaN}$ was higher when compared to the high temperature p-GaN. Nevertheless, this condition is only applicable for the $\mathrm{Cp}_{2} \mathrm{Mg}$ flow rate is less than 500 SCCM [42]. As summarized in Table 2, high resistive nature of five periods in InGaN/GaN MQW structures was observed in comparison to the other two samples (one and three periods). Additionally, it revealed the semiconducting behavior for the all samples.

\section{Conclusion}

In the present study, InGaN/GaN MQW structures were grown by MOCVD on sapphire substrates. The thickness, composition of InGaN well and GaN barriers have been estimated using HRXRD. The InGaN and GaN thicknesses are correlated by cross sectional HR-TEM. FFT analysis demonstrated the $\mathrm{GaN} / \mathrm{InGaN} / \mathrm{GaN}$ lattice plane alignments along the growth direction. From the asymmetric (1 0-1 5) plane RSMs, it was found that the InGaN/GaN MQWs were grown as a coherently strained on the underlying $\mathrm{n}-\mathrm{GaN} / \mathrm{GaN}$ layer. The results indicate that five periods of InGaN/GaN MQWs has better surface interface and crystalline quality. PL study revealed the high intensity green emission in InGaN/GaN MQW (five periods) structures. From AFM results, it was observed that the width and depth of the $\mathrm{V}$ pits increases with increasing of InGaN/GaN MQWs periods. Also step flow growth initiations in the top of $\mathrm{p}-\mathrm{GaN}$ layer on InGaN/GaN MQWs (five periods) were revealed. This can be attributed to the suppression of self-organized In(Ga)N like nanostructures and spiral growth mechanism. Hall measurement results revealed the semiconductor behavior as an effect of increasing the number of the periods in InGaN/GaN MQW structures. This work helps us to understand the growth of InGaN/GaN MQWs structures and its structural, morphological, optical and electrical properties. It can be suitable for the fabrication of high efficiency optoelectronic devices.

\section{Acknowledgement}

The authors gratefully to acknowledge Department of Science and Technology (DST/TM/SERI/2K12/71(G)), Government of India for funding the research project. 


\section{References}

[1] B. Damilano, B. Gil, Yellow-red emission from (Ga, In) N heterostructures, J. Phys. D. Appl. Phys. 48 (40) (2015) 403001.

[2] E. Matioli, C. Neufeld, M. Iza, S.C. Cruz, A.A. Al-Heji, Xu. Chen, R.M. Farrell, S. Keller, S. DenBaars, U. Mishra, S. Nakamura, James Speck, Claude Weisbuch, High internal and external quantum efficiency InGaN/GaN solar cells, Appl. Phys. Lett. 98 (2) (2011) 021102.

[3] R.M. Farrell, A.A. Al-Heji, C.J. Neufeld, X. Chen, M. Iza, S.C. Cruz, S. Keller, S. Nakamura, S.P. DenBaars, U.K. Mishra, J.S. Speck, Effect of intentional p-GaN surface roughening on the performance of InGaN/GaN solar cells, Appl. Phys. Lett. 103 (24) (2013) 241104.

[4] C.C. Yang, J.K. Sheu, X.W. Liang, M.S. Huang, M.L. Lee, K.H. Chang, S.J. Tu, FengWen Huang, W.C. Lai, Enhancement of the conversion efficiency of GaN-based photovoltaic devices with AlGaN/InGaN absorption layers, Appl. Phys. Lett. 97 (2) (2010) 021113.

[5] R.M. Farrell, C.J. Neufeld, S.C. Cruz, J.R. Lang M. Iza, S. Keller, S. Nakamura S.P. DenBaars, U.K. Mishra, J.S. Speck, High quantum efficiency InGaN/GaN multiple quantum well solar cells with spectral response extending out to $520 \mathrm{~nm}$, Appl. Phys. Lett. 98 (20) (2011) 201107.

[6] T.H. Seo, J.P. Shim, S.J. Chae, G. Shin, B.K. Kim, D.S. Lee, Young Hee Lee, E.K. Suh, Improved photovoltaic effects in InGaN-based multiple quantum well solar cell with graphene on indium tin oxide nanodot nodes for transparent and current spreading electrode, Appl. Phys. Lett. 102 (3) (2013) 031116.

[7] M.J. Jeng, Y.L. Lee, Increasing solar efficiency of InGaN/GaN multiple quantum well solar cells with a reflective aluminum layer or a flip-chip structure, J. Electrochem. Soc. 159 (5) (2012) H525-H528.

[8] D.J. Seo, J.P. Shim, S.B. Choi, T.H. Seo, E.K. Suh, D.S. Lee, Efficiency improvement in InGaN-based solar cells by indium tin oxide nanodots covered with ITO films, Opt. Express 20 (106) (2012) A991-A996.

[9] R. Dahal, J. Li, K. Aryal, J.Y. Lin, H.X. Jiang, InGaN/GaN multiple quantum well concentrator solar cells, Appl. Phys. Lett. 97 (7) (2010) 073115.

[10] K. Pantzas, Y. El Gmili, J. Dickerson, S. Gautier, L. Largeau, O. Mauguin, G. Patriarche, S. Suresh, T. Moudakir, C. Bishop, A. Ahaitouf, Semibulk InGaN: a novel approach for thick, single phase, epitaxial InGaN layers grown by MOVPE, J. Cryst. Growth 370 (2013) 57-62.

[11] X.M. Cai, Y. Wang, Z.D. Li, X.Q. Lv, J.Y. Zhang, L.Y. Ying, B.P. Zhang, Improved photovoltaic performance of InGaN/GaN solar cells with optimized transparent current spreading layers, Appl. Phys. A Mater. Sci. Process. 111 (2) (2013) $483-486$.

[12] L. Sang, M. Liao, N. Ikeda, Y. Koide, M. Sumiya, Enhanced performance of InGaN solar cell by using a super-thin AlN interlayer, Appl. Phys. Lett. 99 (16) (2011) 161109.

[13] S. Valdueza-Felip, A. Mukhtarova, Q. Pan, G. Altamura, L. Grenet, C. Durand, Catherine Bougerol, David Peyrade, Fernando Gonza'lez-Posada, Joel Eymery, E. Monroy, Photovoltaic response of InGaN/GaN multiple-quantum well solar cells, Jpn. J. Appl. Phys. 52 (8S) (2013) 08JH05.

[14] L. Sang, M. Liao, Y. Koide, M. Sumiya, InGaN-based thin film solar cells: epitaxy, structural design, and photovoltaic properties, J. Appl. Phys. 117 (10) (2015) 105706.

[15] H. Woo, J. Kim, S. Cho, Y. Jo, C.H. Roh, J.H. Lee, Y.G. Seo, H. Kim, H. Im, C.K. Hahn, Epitaxial growth of low temperature GaN using metal migration enhanced epitaxy for high-quality InGaN/GaN heterojunctions, Superlattice. Microst. 120 (2018) 781-787.

[16] P. Mahala, S. Singh, S. Pal, K. Singh, A. Chauhan, P. Kumar, C. Dhanavantri, Fabrication and characterization of GaN/InGaN MQW solar cells, Appl. Phys. A Mater. Sci. Process. 122 (7) (2016) 1-6.

[17] Z. Xiao-Bin, W. Xiao-Liang, X. Hong-Ling, Y. Cui-Bai, H. Qi-Feng, Y. Hai-Bo, Chen Hon, W. Zhan-Guo, InGaN/GaN multiple quantum well solar cells with an enhanced open-circuit voltage, Chin. Phys. B 20 (2) (2011) 028402.

[18] Y.L. Tsai, S.W. Wang, J.K. Huang, L.H. Hsu, C.H. Chiu, P.T. Lee, Peichen Yu, ChienChung Lin, H.C. Kuo, Enhanced power conversion efficiency in InGaN-based solar cells via graded composition multiple quantum wells, Opt. Express 23 (24) (2015) A1434-A1441.

[19] J. Bai, C.C. Yang, M. Athanasiou, T. Wang, Efficiency enhancement of InGaN/GaN solar cells with nanostructures, Appl. Phys. Lett. 104 (5) (2014) 051129.

[20] V.C. Su, P.H. Chen, R.M. Lin, M.L. Lee, Y.H. You, C.I. Ho, Y.C. Chen, W.F. Chen, C.H. Kuan, Suppressed quantum-confined Stark effect in InGaN-based LEDs with nano-sized patterned sapphire substrates, Opt. Express 21 (24) (2013) 30065-30073.

[21] M.H. Sheen, S.D. Kim, J.H. Lee, J.I. Shim, Y.W. Kim, V-pits as barriers to diffusion of carriers in InGaN/GaN quantum wells, J. Electron. Mater. 44 (11) (2015) 4134-4138.

[22] F.P. Massabuau, L. Trinh-Xuan, D. Lodié, E.J. Thrush, D. Zhu, F. Oehler, T. Zhu, M.J. Kappers, C.J. Humphreys, R.A. Oliver, Correlations between the morphology and emission properties of trench defects in InGaN/GaN quantum wells, J. Appl. Phys. 113 (7) (2013) 073505.

[23] M.S. Kumar, Y.S. Lee, J.Y. Park, S.J. Chung, C.H. Hong, E.K. Suh, Surface morphological studies of green InGaN/GaN multi-quantum wells grown by using MOCVD, Mater. Chem. Phys. 113 (1) (2009) 192-195.

[24] S.C. Tsai, M.J. Li, H.C. Fang, C.H. Tu, C.P. Liu, Efficiency enhancement of blue light emitting diodes by eliminating V-defects from InGaN/GaN multiple quantum well structures through GaN capping layer control, Appl. Surf. Sci. 439 (2018) 1127-1132.

[25] M. Arif, J.P. Salvestrini, J. Streque, M.B. Jordan, Y. El Gmili, S. Sundaram, Xin Li, Gilles Patriarche, Paul L. Voss, A. Ougazzaden, Role of V-pits in the performance improvement of InGaN solar cells, Appl. Phys. Lett. 109 (13) (2016) 133507.

[26] K. Prabakaran, M. Jayasakthi, S. Surender, S. Pradeep, S. Sanjay, R. Ramesh, M. Balaji, K. Baskar, Investigations on morphology, growth mode and indium incorporation in MOCVD grown InGaN/n-GaN heterostructures, Optik 175 (2018) $154-162$.

[27] X. Sun, D. Li, H. Song, Y. Chen, H. Jiang, G. Miao, Z. Li, Short-wavelength light beam in situ monitoring growth of InGaN/GaN green LEDs by MOCVD, Nanoscale Res. Lett. 7 (1) (2012) 1-6.

[28] T.E. Nee, H.T. Shen, J.C. Wang, R.M. Lin, Characterization of Berthelot-type behaviors of InGaN/GaN semiconductor heterosystems, J. Cryst. Growth 287 (2) (2006) 468-471.

[29] Z. Ren, L. Chao, X. Chen, B. Zhao, X. Wang, J. Tong, Jun Zhang, Xiangjing Zhuo, Danwei Li, Hanxiang Yi, S. Li, Enhanced performance of InGaN/GaN based solar cells with an $\mathrm{In}_{0.05} \mathrm{Ga}_{0.95} \mathrm{~N}$ ultra-thin inserting layer between $\mathrm{GaN}$ barrier and $\mathrm{In}_{0.2} \mathrm{Ga}_{0.8} \mathrm{~N}$ well, Opt. Express 21 (6) (2013) 7118-7124.

[30] S. Lazarev, S. Bauer, K. Forghani, M. Barchuk, F. Scholz, T. Baumbach, High resolution synchrotron X-ray studies of phase separation phenomena and the scaling law for the threading dislocation densities reduction in high quality AlGaN heterostructures, J. Cryst. Growth 370 (2013) 51-56.

[31] S. Choi, E. Heller, D. Dorsey, R. Vetury, S. Graham, Analysis of the residual stress distribution in AlGaN/GaN high electron mobility transistors, J. Appl. Phys. 113 (9) (2013) 093510.

[32] P. Stadelmann, JEMS java electron microscopy software, http://cime.epfl.ch/, (2004).

[33] A. Ougazzaden, D.J. Rogers, F.H. Teherani, G. Orsal, T. Moudakir, S. Gautier, V.E. Sandana, F. Jomard, M. Abid, M. Molinari, M. Troyon, Epitaxial MOVPE Growth of Highly c-Axis Oriented InGaN/GaN Films on ZnO-Buffered Si (111) Substrates, International Society for Optics and Photonics, 2010, p. 76031D.

[34] C.M. Tsai, J.K. Sheu, P.T. Wang, W.C. Lai, S.C. Shei, S.J. Chang, C.H. Kuo, C.W. Kuo, Y.K. Su, High efficiency and improved ESD characteristics of GaN-based LEDs with naturally textured surface grown by MOCVD, IEEE Photon. Technol. Lett. 18 (11) (2006) 1213-1215.

[35] Z. Chen, L.W. Su, J.Y. Shi, X.L. Wang, C.L. Tang, P. Gao, AFM application in IIInitride materials and devices, Atomic Force Microscopy-Imaging, Measuring and Manipulating Surfaces at the Atomic Scale, InTech, 2012.

[36] H.M. Ng, T.D. Moustakas, K.F. Ludwig Jr., Structural and optical characterization of InGaN/GaN multiple quantum wells grown by molecular beam epitaxy, J. Vac. Sci. Technol. B 18 (3) (2000) 1457-1460.

[37] W. Liu, J. Yang, D. Zhao, D. Jiang, J. Zhu, P. Chen, Z. Liu, F. Liang, S. Liu, Y. Xing, L. Zhang, Energy band tilt in ultra-thin InGaN film affected by the surface adsorption and desorption, Appl. Surf. Sci. 456 (2018) (2018) 487-492.

[38] Y. Chen, H. Wu, G. Yue, Z. Chen, Z. Zheng, Z. Wu, Gang Wang, H. Jiang, Enhanced $\mathrm{Mg}$ doping efficiency in p-type GaN by indium-surfactant-assisted delta doping method, Appl. Phys. Express 6 (4) (2013) 041001.

[39] U. Kaufmann, M. Kunzer, M. Maier, H. Obloh, A. Ramakrishnan, B. Santic, P. Schlotter, Nature of the $2.8 \mathrm{eV}$ photoluminescence band in $\mathrm{Mg}$ doped GaN, Appl. Phys. Lett. 72 (11) (1998) 1326-1328.

[40] M.R. Correia, S.M.D.S. Pereira, E. Pereira, R.S. Ferreira, J. Frandon, E. Alves, I.M. Watsonf, C. Liuf, A. Morel, B. Gil, Optical studies on the red luminescence of InGaN epilayers, Superlattice. Microst. 36 (4) (2004) 625-632.

[41] H. Obloh, K.H. Bachem, U. Kaufmann, M. Kunzer, M. Maier, A. Ramakrishnan, P. Schlotter, Self-compensation in Mg doped p-type GaN grown by MOCVD, J. Cryst. Growth 195 (1998) 270-273.

[42] J. Ju, J. Zhu, H. Kim, C. Lee, I. Lee, Effects of p-GaN growth temperature on a green InGaN/GaN multiple quantum well, J. Korean Phys. Soc. 50 (3) (2007) 810. 